\title{
Analytical and Experimental Studies of Rapid Cloth Drying for Technological Innovation
}

\author{
Atcharaporn Chailoet, Tanapon Kliniam ,Ranet Muangpisan , Peerawich Kiatkungwankai, and Thananchai \\ Leephakpreeda. \\ School of Manufacturing Systems and Mechanical Engineering , Sirindhorn International Institute of Technology, Thammasat University , \\ Thailand
}

\begin{abstract}
This paper presents analytical and experimental studies of a rapid cloth drying process. The mathematical models are developed from mass diffusion of wet clothes under hot and dry air conditions There are three critical factors: air temperature, air humidity, and the mass transport coefficient. Experiments of outdoor cloth drying are investigated as a benchmark. It is found drying duration is about 2-3 hours for satisfactory drying states under sunny weather. To reduce drying period, the mass transport coefficient is the highest sensitive factor while it can be adjusted by air speed through clothes. Experimental results of a rapid cloth drying heat pump show that the drying period can be reduced to 12 minutes with COP of 5.4. This understanding is able to strengthen development of rapid cloth drying for technological innovation.
\end{abstract}

\section{Introduction}

Nowadays, the most preferable way of cloth drying is to hang laundry cloths outside under sunny weather with clean outdoor air. This primitive process yields free and wide availability, and even whitens white cloths with fresh smell. However, the outdoor cloth drying is not always impeccable since it is not controllable due to changes of environment. For example, fading and stretchy spots are caused by ultra violet rays of sunlight, excessively pointing to colored clothes in summer. Additionally, there are some regulations about home clotheslines, which lower and endanger property values of communities, where a specific area is reserved for direct sunlight without bird dropping or/and insect specks. Particularly, outdoor cloth drying is not ideal under rainy season and polluted environment with dirty outdoor air. Many cloths drying technologies have been developed to overcome those limitations of outdoor cloth drying [1-4]. Mainly, laundry cloths are dried under a virtual outdoor environment of a cloth dryer, which is filled with hot, dry, and clean air. In Thailand, the weather is hot but humid all year long. Washing clothes is necessary everyday due to sweating on clothes [5]. In turn, there is dramatically increasing requirement for cloth drying in a short period. Understanding of a rapid cloth drying is needed to develop technologies of cloth drying under not only unsuitable climate but also tight schedule.

To comprehend a rapid cloth drying, critical factors of cloth drying process are studied in this work such as temperature of surrounding air, humidity, and air speed through cloth surface. Up to now, there has not been any case of performance investigation on interacting effects of those factors on cloth drying process in literature. Most previous works focus on control of air temperature and humidity in food drying processes [6-7]. For example, implementation of high temperature of air and low velocity has been recently investigated under convective deep-bed drying conditions of rough rice [8]. It was found that energy consumption can be lowered from determination of air conditions. Also, this result indicates relationship between air temperature and convection heat transfer from air velocity. In [9], drying kinetics of mint leaves in tunnel dryer was developed for effectively increase moisture diffusivity from rise of drying air temperature. This paper presents sensitivity analysis of the cloth drying factors on drying period, which performance index for a rapid drying process. Thus, optimal conditions can be chosen according to those results for development of experiments.

For the outline of this paper, the experimental setup in section 2 is briefly explained for understanding the cloth drying process and equipment implementation of this work. In section 3, mathematical models of cloth drying are derived in terms of drying factors for determination of sensitivity to drying period in the process. Analytical results and experimental results are discussed on reducing the drying period based on benchmark of outdoor cloth drying in section 4 . The conclusion is remarked for advantageous findings in choosing critical drying factors of rapid cloth drying process in section 5 . 


\section{Experiment setup}

Fig. 1 presents a diagram of a cloth drying process, which is thermally driven by a heat pump in this experimental work. The cloth dryer of $0.23 \mathrm{~kW}$ consumes electrical energy to cause cooling effect at evaporator with absorbed heat from supply air and heating effect at condenser with rejected heat to supply air. The heating output of the cloth dryer is implemented to increase air temperature while the cooling output of the cloth dryer is applied to decrease humidity ratio of a supply air. In other words, the water moisture is removed by condensation while the supply air pass through an evaporator. The dry supply air is heated to high temperature for cloth drying inside a chamber of cloth dryer. An electric blower of $0.32 \mathrm{~kW}$ is used to drive supply air into a cloth drying chamber with high speed.

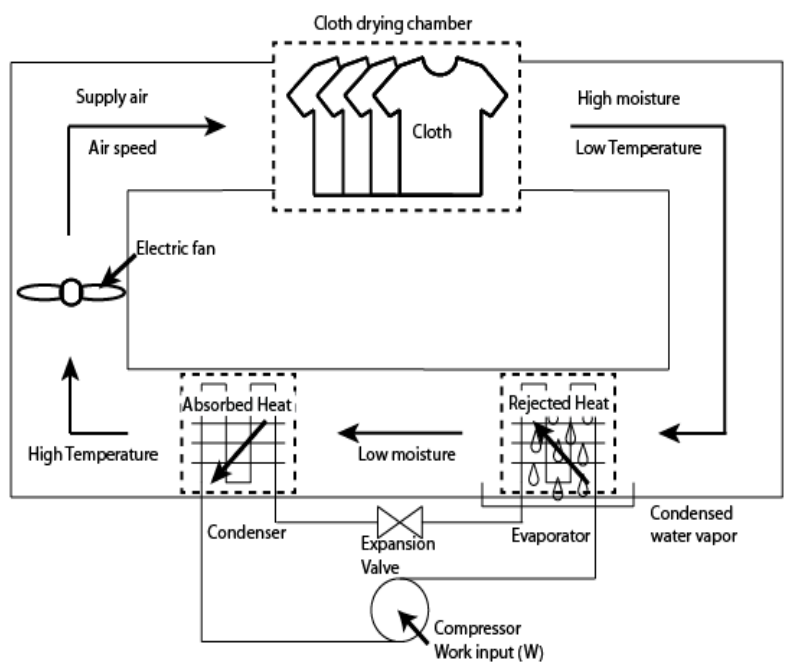

Figure 1. Diagram of cloth dryer driven by heat pump.

\section{Analysis of rapid cloth drying process}

In Fig. 1, a cloth drying process, within cloth drying chamber, is removal of excessive moisture from wet clothes since moistures within clothes and surrounding air are unbalanced. At the cloth surface, concentration of water vapor is higher than surrounding air where water vapor diffuses away from the clothes. Let define the moisture concentration in cloth to be:

$$
M=\frac{m_{w}}{m_{c}}
$$

where $m_{w}$ is the mass of water moisture in cloth, and $m_{c}$ is the mass of dry cloth

According to Fick's law [10], the diffusive flux of water moisture between the cloth surface and surrounding air can be governed by:

$$
\frac{d M}{d t}=h_{m}\left(M_{\infty}-M\right)
$$

where $h_{m}$ is the mass transport coefficient that is strongly function of air speed, and $M_{\infty}$ is the moisture concentration in air.

With the state equation of ideal gas [11], the moisture concentration in air can be related to humidity ratio of air as:

$$
M_{\infty}=\left(\frac{P_{a} V_{a} / R T_{a}}{m_{c}}\right) \omega_{a}
$$

where $\omega_{a}$ is the absolute humidity of air, $P_{a}$ is the pressure of dry air, $V_{a}$ is the effective volume of dry air surrounding cloth, $R$ is the specific gas constant of dry air, and $T_{a}$ is the air temperature.

Due to small ratio of volume to the cloth surface, there is an assumption on uniformity of water moisture in fabric. From (1)-(3), it can be interpreted that the diffusive flux of water moisture at the cloth surface is dependent on the air temperature and the humidity ratio of air. The higher the air temperature, the more the diffusive flux of water moisture whereas the lower the humidity ratio of air the more the diffusive flux of water moisture. In addition, the mass transport coefficient is proportionally varied according to air speed [12]. To obtain a rapid cloth drying, a cloth dryer is to increase air temperature and the mass transport coefficient by adjusting air speed through the clothes while it is to lower humidity ratio of air.

Therefore, the critical drying factors such as air temperature, humidity ratio of air, and the mass transport coefficient are studied in sensitivity analysis. The sensitivity analysis of performance indices to drying factors is done to identify the contributions of each drying factor in improving performances of a cloth dryer. Effects of the drying factors to performances of a cloth dryer can be determined by sensitivity $S$ in (4).

$$
S=\frac{F\left(x^{\prime}\right)-F(x)}{F(x)} \times 100 \%
$$

where $F$ is the performance index, $x$ is the drying factors at given operating condition, and $x^{\prime}$ is the drying factors whose the magnitude is changed by $+5 \%$, or $-5 \%$, and $+10 \%$, or $-10 \%$ from the operating condition.

For performance index of a rapid drying process, the drying period $t_{d}$ is defined as the duration of the wet cloth mass decreasing to mass of the dry cloth.

As shown in Fig. 1, the coefficient of performance ( $C O P$ ) is the ratio of heating/cooling output to the required power input of a cloth dryer.

$$
C O P=\frac{Q_{H}+Q_{C}}{W}
$$


where $Q_{H}$ is the heating output of condenser in raising air temperature, $Q_{C}$ is the cooling output of evaporator in condensing water vapor, and $W$ is the required power input of compressor and electric blower.

\section{Results and discussion}

The experiments of outdoor cloth drying are investigated under various weather conditions for a benchmark. The same amount of laundry clothes are prepared from a washing machine. Table 1 reports three distinguished examples of daily averaged air temperature (AT), relative humidity $(\mathrm{RH})$, weather (WEA), drying period (P), and interview about satisfaction on finished clothes (I). It can be observed that wet clothes take about 2-3 hours in complete outdoor drying. Particularly, the final states of dried clothes are unsatisfied unless the weather is sunny and clear.

Table 1. Experiments of drying clothes under outdoor air

\begin{tabular}{|c|c|c|c|c|c|}
\hline & AT $\left({ }^{\circ} \mathbf{C}\right)$ & $\begin{array}{c}\text { RH } \\
(\%)\end{array}$ & WEA & P(hrs) & I \\
\hline 1 & 32 & 58 & Cloudy & 2.5 & Very good \\
\hline 2 & 29 & 76 & Rainy & $>3$ & Poor \\
\hline 3 & 33 & 57 & Sunny & 2 & Excellent \\
\hline
\end{tabular}

For comparison between case 1 and case 3, the more sunny the weather, the shorter the drying duration. In high humid ambient air, the satisfaction to dried clothes is unacceptable even though the drying duration lasts for more than 3 hours. This interpretation means that ambient air has increase in humidity and a decrease in temperature. Consequently, this situation leads to an unpleasant quality of cloth condition.

Fig. 2 shows plots of satisfaction scales under cloth drying conditions in psychrometric chart for all experiments. There are five scales of satisfaction: excellent, very good, good, fair, and poor, as indicated in colors. It can be seen that high temperature and low humidity of ambient air are the most superior conditions for outdoor cloth drying.

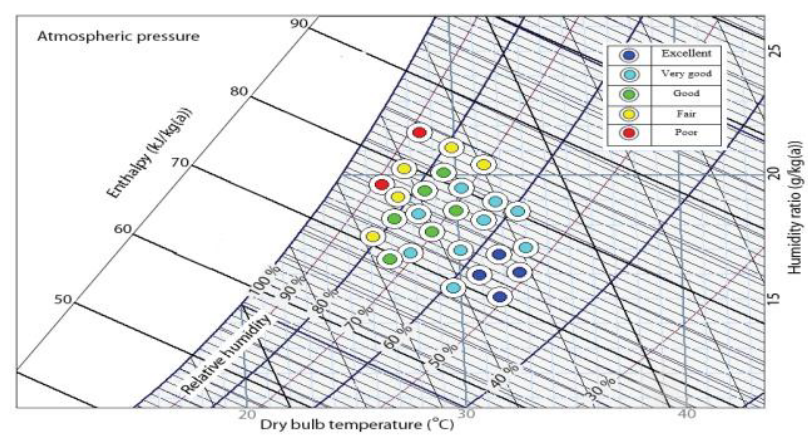

Figure 2. Satisfactions under cloth drying cloth conditions in psychrometric chart.
To obtain effective performance of a rapid cloth drying process, accessible variables are determined from important drying factors. The sensitivity analysis is applied to identify the most effective factors in order to satisfy objectives of rapid cloth drying. From (1)-(3), the mathematical models of cloth drying are solved for drying periods with an initial condition of dried clothes under an air-conditioned room as listed in Table 2.

Table 2. Numerical values of some properties.

\begin{tabular}{|l|l|}
\hline Properties & Numerical values \\
\hline Mass of dry cloth, $m_{c}$ & $155.82 \mathrm{~g}$ \\
\hline Moisture concentration in air, $M_{\infty}$ & $0.014311 \mathrm{~kg} / \mathrm{kg}(\mathrm{dc})$ \\
\hline Specific gas constant of dry air, $R$ & $0.287 \mathrm{~J} / \mathrm{kgK}$ \\
\hline Pressure of dry air, $P_{a}$ & $101.325 \mathrm{kPa}$ \\
\hline Effective volume of dry air, $V_{a}$ & $0.253 \mathrm{~m}^{3}$ \\
\hline Air temperature, $T_{a}$ & $27^{\circ} \mathrm{C}$ \\
\hline Absolute humidity of air, $\omega_{a}$ & $0.009 \mathrm{~kg} / \mathrm{kg}(\mathrm{a})$ \\
\hline Heating output of condenser, $Q_{H}$ & $1.56 \mathrm{~kW}$ \\
\hline Cooling output of evaporator, $Q_{C}$ & $1.39 \mathrm{~kW}$ \\
\hline $\begin{array}{l}\text { Power input of compressor and } \\
\text { blower, } W\end{array}$ & $0.55 \mathrm{~kW}$ \\
\hline
\end{tabular}

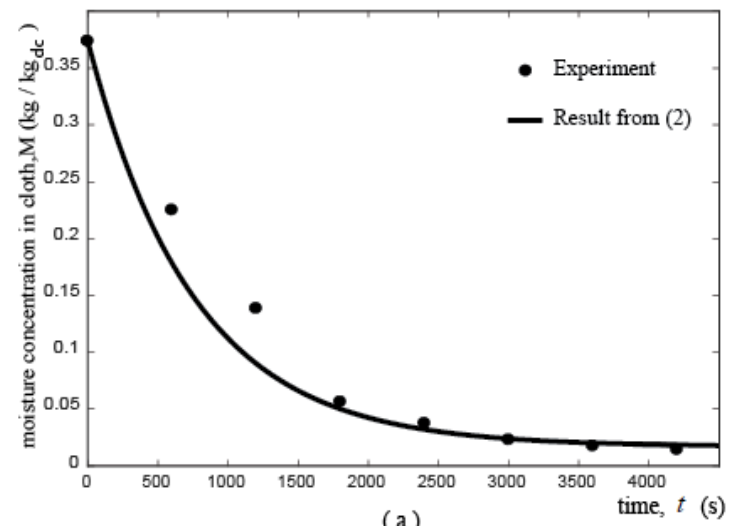

(a)

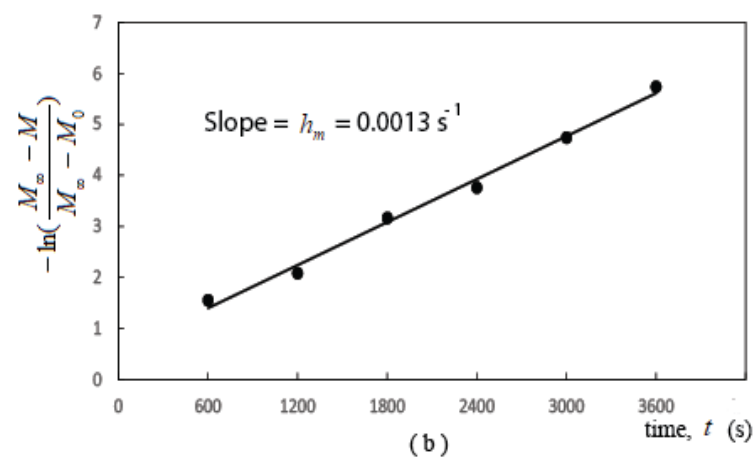

Figure 3. Cloth drying: (a) results and (b) linear regression.

In Fig. 3(a), the dotted line indicates experimental results of moisture concentration in a sample cloth, which has dry mass of $155.82 \mathrm{~g}$ during the drying process. The wet cloth is set with the initial moisture concentration 
$M_{o}$ of $0.375 \mathrm{~kg} / \mathrm{kg}_{\mathrm{dc}}$. The moisture concentration decreases to the dry state within 75 minutes. It can be noted that this drying period is shorter than outdoor drying period since the humidity in the air-conditioned room is lower than ambient air. The solid line represents the simulated results of (1)-(3) where the mass transport coefficient of this drying condition is determined from the slope of linear regression, as illustrated in Fig. 3(b). From observation, the simulated results have good agreement with the experimental results. Therefore, the mathematical model (1)-(3) with parametric values are applied for sensitivity analysis in (4). The drying period is determined by varying the critical factors with given percentages such as humidity ratio, air temperature, and the mass transport coefficient in (1)-(3).

According to Fig. 4(a) and Fig. 4(b), the results of sensitivity analysis are graphically presented when changes of air temperature, humidity ratio, and the mass transport coefficient are defined in percentages of $5 \%$ and $10 \%$, respectively.

It is found that increasing the mass transport coefficient by $5 \%$ and $10 \%$ is superior since decreasing drying period with the greatest percentages, which are compared to humidity ratio and air temperature. On the other hands, air temperature has the lowest impact on drying period. Increasing the mass transport coefficient is the most effective way when the rapid cloth drying process is needed to be improved. Increasing the mass transport coefficient by results in changes of the drying period.

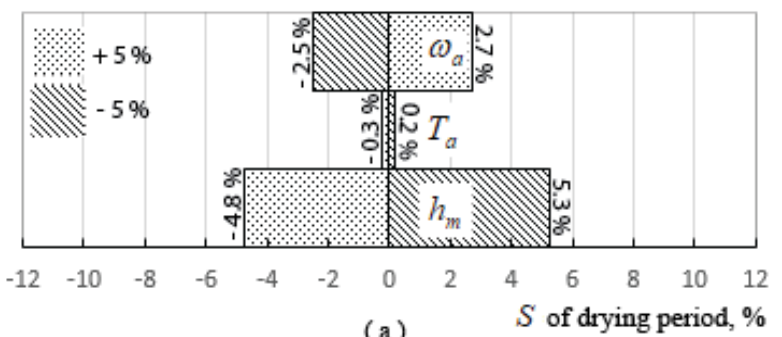

(a)

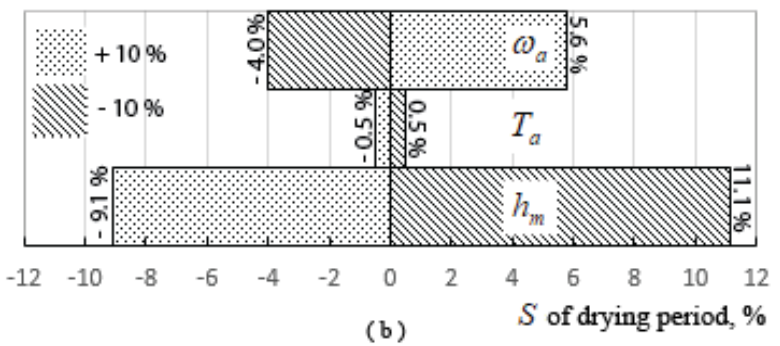

Figure 4. Sensitivity analysis of drying factors.

To see effects of the mass transport coefficient on the drying period for a rapid drying process, experimental rig is developed to increase air speed by implementing a blower through the wet cloth of T-shirt under an airconditioned chamber as illustrated in Fig. 5 where the details of functions are described in section II.

In this experiment, the electric blower is uses to supply made-up air at high air speed of $11 \mathrm{~m} / \mathrm{s}$ along drying chamber. The development of design yields drying time of 12 minutes and COP of 5.4. The drying period is significantly reduced with acceptable efficiency of energy usage.

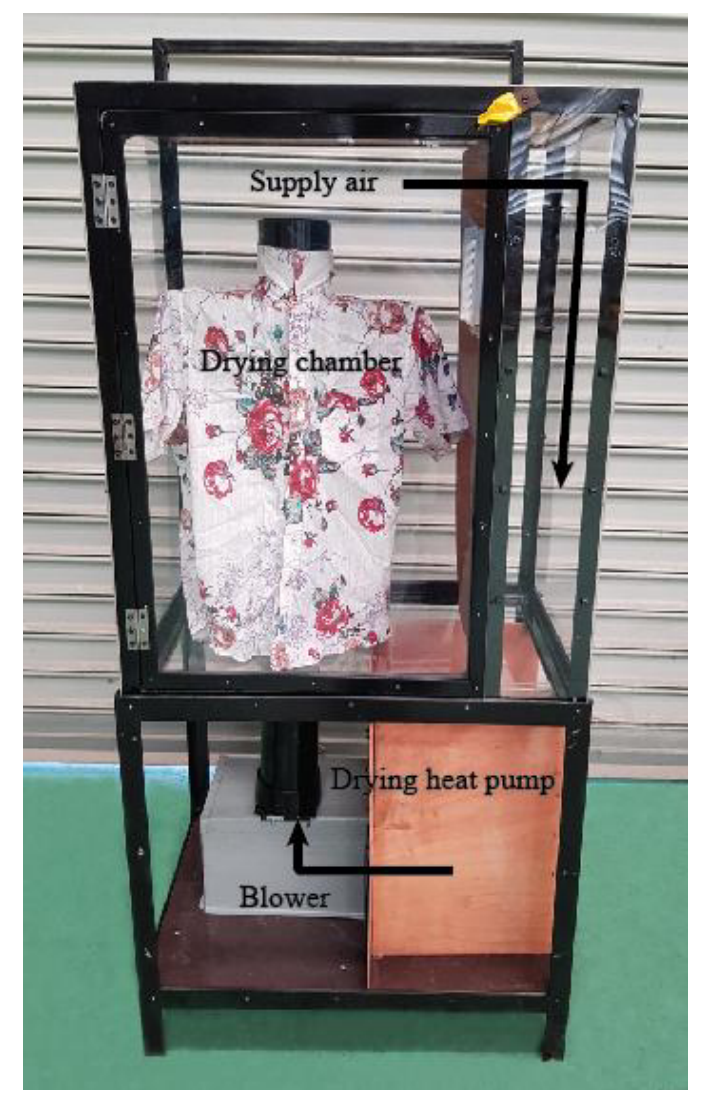

Figure 5. Development of rapid cloth drying machine.

\section{Conclusion}

In this work, the mathematical models of moisture diffusion from wet cloths to ambient surrounding are proposed to describe a cloth drying process. Based on those quantitative knowledge, sensitivity analysis is applied to be able to identify the most critical drying factor to shorten drying period, that is the mass transport coefficient among other factors such humidity ratio and temperature of air. In experiment, the adjustment of the mass transport coefficient is to increase air speed for shortening drying period significantly with acceptable efficiency of energy usage. It is found drying duration is about 2-3 hours for satisfactory drying states under sunny weather. Experimental results of a rapid cloth drying heat pump show that the drying period can be reduced to 12 minutes with COP of 5.4. For future works, the mass transport coefficient is to be investigated for quantifiable relation of air speed to the cloth drying processes for real time control implementation. The optimal performances for rapid cloth drying and low energy consumption are also considered.

\section{References}

1. C. Peng, S. Ravi, V.K. Patel, A.M. Momen, S. Moghaddam, Energy 125, (2017). 
2. E. Martin, K. Sutherland, D. Parker, ACEEE summer study on energy efficiency in buildings (2016).

3. A.M. Momen, K.R. Gluesenkamp, E.A. Vineyard, R.A. Kisner, PCT/US2016/030885 (2015).

4. P. Xu, X. Ma, X. Zhao, K.S. Fancey, Building Environ. 110, (2016)

5. T. Leephakpreeda, Expert Syst Appl. 34, 4 (2008).

6. T. Defraeye, P. Verboven, J. Food Eng. 193, (2017)

7. E. Barati, J.A. Esfahani, J. Food Eng. 102, (2011)

8. M. Beigi, M. Torki-Harchegani, M. Tohidi, Energy 141, (2017)
9. D.M. Kadam, R.K. Goyal, K.K. Singh, M.K. Gupta, J. Med Plants Res. 5, 2 (2011)

10. A. Paul, T. Laurila, V. Vuorinen, S.V. Divinski, Thermodynamics, diffusion and the Kirkendall effect in solids (2014)

11. Hand book of compressed gases, Arlington, Virginia: Compressed Gas Association, Inc. (1990)

12. D.F. Barbin and V.S. Junior, Heat TransferTheoretical Analysis, Experimental Investigations and Industrial Systems, InTech, (2011) 